\title{
Recollection and Taxonomic Placement of Alpinia apoensis (Zingiberaceae; Alpinioideae): An Imperfectly Known Philippine Endemic Species
}

\author{
Mark Arcebal K. Naive ${ }^{1 *}$, Jade Ann Grace P. Dalisay ${ }^{2}$, Porferio S. Bangcaya ${ }^{2,3}$, Grecebio Jonathan \\ D. Alejandro ${ }^{4}$ \\ ${ }^{1}$ Department of Biological Sciences, College of Science and Mathematics, Mindanao State University-Iligan \\ Institute of Technology, Iligan City 9200, Philippines \\ ${ }^{2}$ Biological Science Department, College of Teacher Education, University of Antique, Tario-Lim Memorial \\ Campus, Tibiao, Antique 5707, Philippines \\ ${ }^{3}$ University of Antique, Libertad Campus, Libertad, Antique 5711, Philippines \\ ${ }^{4}$ College of Science, Research Centre for the Natural and Applied Sciences, University of Santo Tomas, Manila \\ 1015, Philippines
}

Article history:

Submission October 2018

Revised January 2019

Accepted January 2019

*Corresponding author:

E-mail: arciinaive19@gmail.com

\begin{abstract}
A recent exploration on the Mt. Kalatungan Range Natural Park of Bukidnon and Mt. Madjaas of Antique resulted in the recollection of Alpinia apoensis. It is an endemic Zingiberaceae species of uncertain identity that was first collected and described by Elmer over 90 years ago. As there is no comprehensive revision of the family Zingiberaceae in the Philippines, it is meanwhile important to clarify its taxonomic identity. This study contributes a comprehensive description of the species leading to the determination of its sectional and subsectional placements. Information on its geographical distribution, phenology, ecology, and coloured photographs are also provided.
\end{abstract}

Keywords: Alpinieae, sect. Alpinia, Antique, endemic, subsect. Presleia, Zingiberaceae

\section{Introduction}

The family Zingiberaceae, represented by 56 genera and about 1337, is distributed mainly in the tropics and subtropics with its centre of distribution in Southeast Asia [1, 2]. Alpinia Roxb. is the largest genus in the family, represented by approximately 230 species distributed across Southeast Asia to Australia [3]. In the Philippines, about 37 species are recorded so far [4].

Materials of an interesting unknown Alpinia specimens were collected during the first author's expedition in the Mt. Kalatungan Range Natural Park (MKaRNP), Bukidnon, Philippines last October 2015. In October 2017, the second and third authors collected the same species in Mt. Madjaas, Antique. After a meticulous examination of its morphology including protologues and digitized type specimens of Alpinia species from the Phili- pines, it matches with the imperfectly known $\mathrm{Al}$ pinia apoensis in having ovately oblong to oblong leaves with sharply acuminate, recurved apex, fruits ovoid to obovoid, green to yellow and becoming dull red when matured. This species is recollected after more than 90 years. Like many other Zingiberaceae species in the country, no botanical illustrations or photographs were ever published, adding to the unclear identity of this species [5]. A. apoensis was described by Elmer (1915) based on the specimen collected from the province of Davao del Sur [6]. The next short note on this taxon appeared some 7 years later in Enumeration of Philippine Flowering Plants where Merill (1922) transferred the species as Languas apoensis (Elmer) Merr. Ramos and Edano have then recollected it in the province of Catanduanes on 18 August 1928, however, no flowers have also been

\section{How to cite:}

Naive MAK, Dalisay JAGP, Bangcaya PS, Alejandro GJD (2019) Recollection and Taxonomic Placement of Alpinia apoensis (Zingiberaceae; Alpinioideae): An Imperfectly Known Philippine Endemic Species. Journal of Tropical Life Science 9 (1): 65 - 70. doi: 10.11594/jtls.09.01.09 
observed [7]. Smith (1990) then considered the taxon as an imperfectly known species due to the fact that the type specimens designated by Elmer as well as the collections of Ramos and Edano have no flowers [8]. Thus, its sectional and subsectional placements in the family remain uncertain. Recollection of this interesting endemic species allowed a detailed taxonomic account in the family.

\section{Material and Methods}

The measurements and descriptions were based on fresh, dried, and spirit materials. The terminology in general follows Beentje (2016) [9]. Flowers were preserved in formalin-acetic-acidalcohol (FAA) for further study. All original materials under Alpinia sect. Alpinia subsect. Presleia from the Philippines were examined in different herbaria (viz. BM, C, E, FI, G, GH, K, L, P, PR, S, U, US, W) through high-resolution images accessed at https://plants.jstor.org/. Detailed descriptions and coloured photographs of the species as well as notes on its distribution, phenology, and ecology are provided.

\section{Results and Discussion}

Alpinia apoensis Elmer, Leafl. Philipp. Bot. 8: 2888, 1915. (Figure 1)

Type: PHILIPPINES, Mindanao, Davao del Sur, Todaya, Mt. Apo, elev. 1335 m, Sept. 1909, Elmer A.D.E. 11889 (lectotype: NY [00320208 \& NY00320186], designated here; isolectotypes: BISH1005374, F0047144F, G00008021, GH00030629, P00686661, U0007203).

(=) Languas apoensis (Elm.) Merr. in Enum. Philipp. Fl. Pl. 230. 1923.

Terrestrial, perennial herb. Rhizome at or just below the soil, yellowish brown externally, covered with papery thin sheath, $1-2 \mathrm{~cm}$ in diameter. Leafy shoots erect to slightly ascending, green with small white patches, glabrous to pulverulent, 3-6 mm in diameter, loose clump of $2-5$ shoots, shoot $0.8-1.5 \mathrm{~m}$ tall with 14-22 leaves, base slightly swollen. Leaves petiolate, subcoriaceous, ascending, $10-17 \mathrm{~cm}$ long; ligule hyaline red to green, oblong to elliptic, puberulent, $1-5 \mathrm{~mm}$ long, apex rounded to truncate, sparsely ciliated; petiole short, yellowish green, canaliculate, puberulent, 5-8 mm long; blades ovately oblong to oblong, adaxially sparsely pubescent, green, shiny, abaxi- ally densely pubescent, paler green, $10-16 \mathrm{~cm}$ by 4-5.4 cm, margin entire to wavy, apex acuminate, recurved; midrib adaxially pale green, canaliculate, sparsely puberulent, abaxially protruding, densely puberulent. Inflorescence thyrse, erect, up to $10 \mathrm{~cm}$ long; flowers bearing part light green, pubescent, 15-23 cm long; peduncle green, 5-7 cm long; bracts oblanceolate, papery, brown, dorsally pubescent, up to $35 \mathrm{~cm}$ long, usually dried when flowering; bracteoles not seen; Flowers $2-3$ per cincinnus; pedicel very short, pubescent, $2-3 \mathrm{~mm}$ long; calyx tublar, striate, white, $1-1.2 \mathrm{~cm}$ long, inflated, trilobed, incision 1-1.5 mm long, acute, apex sparsely or minutely hairy; corolla tube longer than calyx, white, partially translucent, glabrous, 1.2-1.4 cm long; dorsal corolla lobe elliptic, cucullate, concave, with numerous distinct veins, $5-6$ by $3-4 \mathrm{~mm}$, glabrous, apex obtuse; lateral corolla lobes narrowly elliptic, cucullate, concave, with numerous distinct veins, $5-6$ by $2-3$ $\mathrm{mm}$, glabrous, apex obtuse; lateral staminodes obscure, white to purplish, acicular, inclined, glabrous, 1-1.2 mm long, apex acute; labellum 4 lobed, cuneiform-broadly obovate, white with purple bands, slightly fleshy, glabrous, $5-7$ by 3$4 \mathrm{~mm}$, lateral lobes $4-5$ by $2 \mathrm{~mm}$, entire, elliptic, apex obtuse, midlobe 5-6 by 1.5-2 $\mathrm{mm}$, entire to erose, slightly recurved, apex emarginate to retuse; stamen arching, slender, 1-1.1 cm long; filament slightly fleshy, whitish, sparsely puberulent, $0.7-0.8 \mathrm{~cm}$ long; anther 3-3.5 cm long, with a small entire anther crest; ovary globose, sparsely puberulent, 2.5-3 mm long; style 1.8-2 cm long, glabrous; stigma infundibuliform, apex ciliated; epigynous gland 2, entire, 3-4 mm long, clasping the base of the style. Fruits ovoid, green to yellow when young, becoming obovoid, dull red when matured, shiny, glabrous, $0.8-1$ by $0.6-0.7 \mathrm{~cm}$.

\section{Distribution}

This Philippine endemic species has been observed and documented in Catanduanes of Luzon; Davao Del Sur and Bukidnon of Mindanao; and Antique of Visayas (Figure 2) [5, 6].

\section{Ecology}

Terrestrial herb found growing in montane evergreen broad-leaved close canopy primary forest with damp soil and humid environment at elevations 1,400 to 1,900 meters above sea level. 

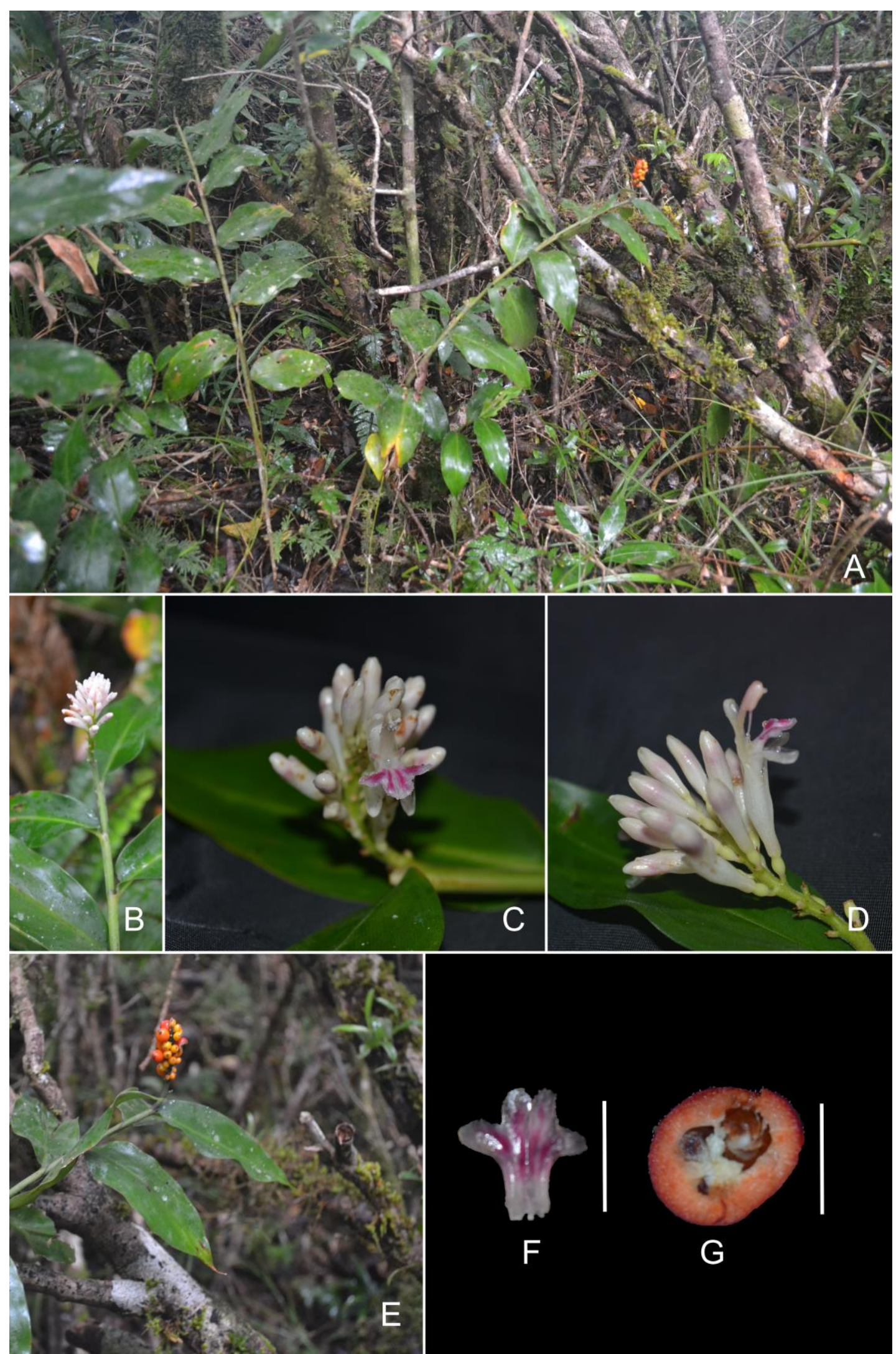

Figure 1. A. apoensis Elmer. A. Habit B. Inflorescence C. Detail of flower (front view) D. Detail of flower (profile view) E. Infructescence F. Detail of labellum (scale bar: $5 \mathrm{~mm}$ ) G. Dissected fruit (scale bar: 7 mm). Photos by: Jade Ann Grace Dalisay. 


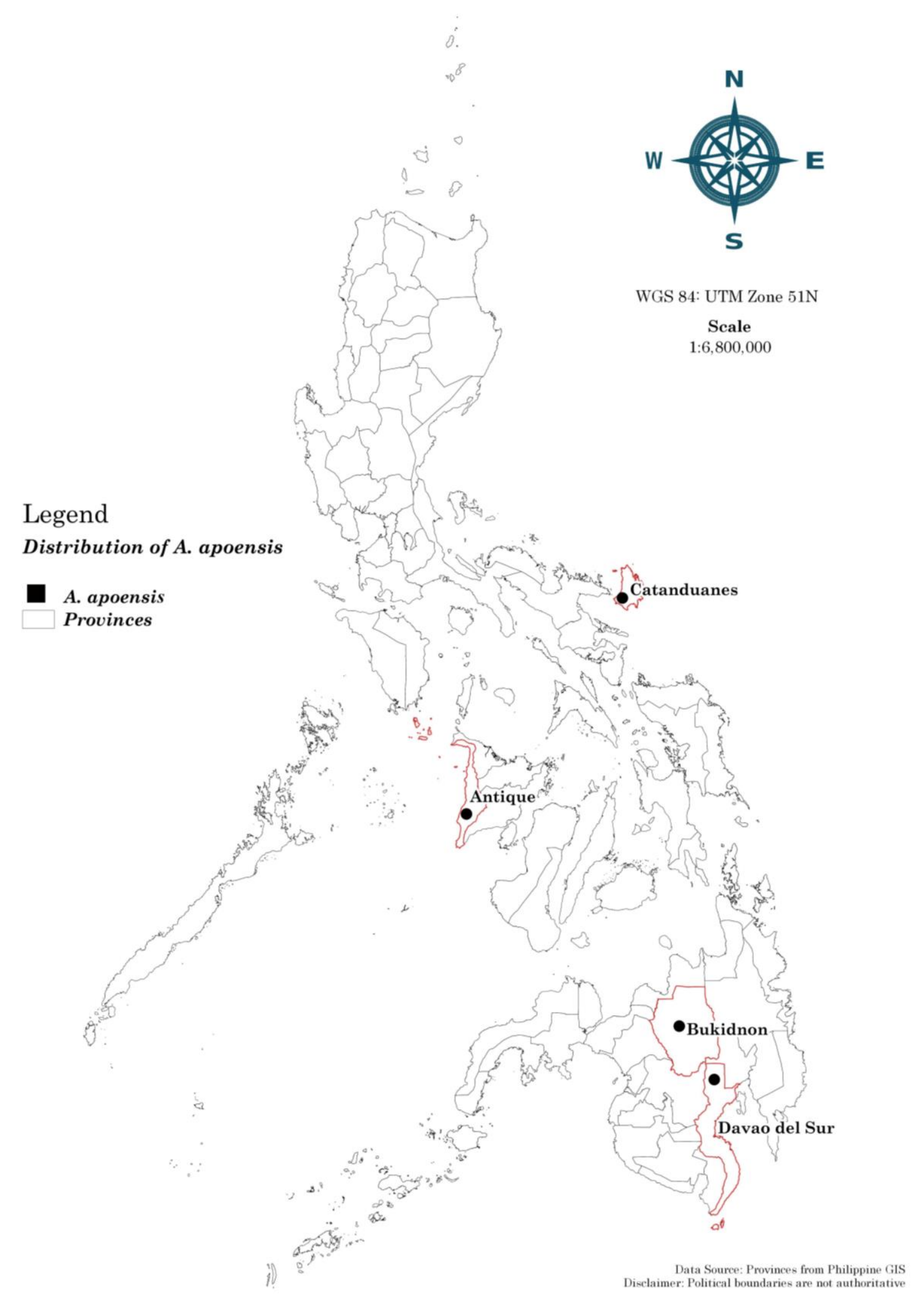

Figure 2. Distribution map of A. apoensis Elmer 


\section{Phenology}

Observed flowering and fruiting from July to November.

\section{Etymology}

The species was described by Elmer (1915) [6] and the specific epithet denotes the type locality where the specimens were first collected.

\section{Vernacular name}

Known as "Otin-otin" by the local people of the type locality or Bagobo [6].

\section{Conservation status}

The area of distribution of A. apoensis is about $1,600 \mathrm{~km}^{2}$ and consists of less than 10 localities, mainly in the Mt. Kalatungan Range Natural Park. Based on the IUCN Red List Categories and Criteria [10], we propose a conservation status of Vulnerable (VU B1ab(iii)). However, as the habitat of $A$. apoensis is affected by human activities and is in decline, the taxon is likely to qualify in the near future for the Endangered category.

\section{Specimens examined}

PHILIPPINES, Mindanao, Bukidnon, Municipality of Pangantucan, Baranagay Portulin, Mt. Kalatungan Range Natural Park, 1537 m, along the forest trail, 31 October 2015, M.A. Naive 02/2015 (CMUH); Visayas, Antique, Municipality of Culasi, Mt. Madjaas, 1,450 m, 17 October 2017, J.A.G. Dalisay 001/2017 (new provincial record, USTH).

Alpinia apoensis is one of the least known Zingiberaceae species in the Flora of the Philippines. This species was first collected by Elmer in 1909 and introduced to science in 1915 . There are some deficiencies in the description of the type specimen due to a lack of flower and was evaluated as “species imperfectly known” by Smith (1990) [8]. Lack of flowers makes the determination of its section and subsection impossible. Thus, recollection of the species in full bloom on its natural habitat has made it possible to describe the species in detail. Furthermore, its sectional and subsectional placements were clarified.

By having an erect, branched inflorescence; bracts often soon deciduous; flowers in cicinni, very small; labellum 4-lobed; filament well formed; stigma infundibuliform, small; epigynous gland narrow, ventrally fused; and fruits ovoid indicate that this taxon belongs to section Alpinia subsection Presleia. Subsection Presleia is a welldefined group, which is distributed in Malaysia, Indonesia, New Guinea, Japan, Taiwan and the Philippines.

Based on overall morphology, Alpinia flabellata and Alpinia graminea, are the closest ally of A. apoensis. However, it differs significantly with A. flabellata Ridl. [11] in having a shorter leafy shoot (up to $1.5 \mathrm{~m}$ tall vs. up to $3 \mathrm{~m}$ tall), oblong to elliptic ligule (vs. ovate), narrowly ovate to ovate leaves (vs. narrowly lanceolate leaves), shape of the corolla lobes and emarginate to truncate midlobe of the labellum (vs. bifid midlobe of the labellum). A. apoensis is also comparable to $A$. graminea Ridl. however, it differs significantly in having a narrowly ovate to ovate leaves (vs. linear leaves), presence of petiole or petiolate (vs. sessile) and emarginate to truncate midlobe of the labellum (vs. deeply bifid).

Elmer (1915) in his original description cited the type as "Type specimen number 11889, A.D.E. Elmer, Todaya (Mt. Apo), District of Davao, Mindanao, September 1909" [6]. We were able to trace eight sheets that are all designated as isotypes, as to where the holotype is unknown. We hereby designate the best sheet NY (NY00320208 \& NY00320186) as the lectotype of A. apoensis as it has the same date and it agrees well with the protolougue. All other specimens with an identical collection number and collection dates mentioned in the protologue, i.e. September 1909 (BISH1005374, F0047144F, G00008021, GH00030629, P00686661, U0007203) are treated here as isolectotypes.

\section{Conclusion}

Botanical excursions in the MKaRNP and Mt. Madjaas has led to the rediscovery of A. apoensis after a lapse of over a century. The species clearly belongs to sect. Alpinia subsect. Presleia based on the morphological features stated above. With this finding, there are now thirteen (13) species under subsect. Presleia in the Philippines.

\section{Acknowledgment}

The following are acknowledged for their valuable help in completing this paper: Dr. Daniel Geiger, Dr. Mark Newman, Dr. Hidenobu Fu- 
nakoshi, Mr. Casey Clark Sumalinog, Mr. Timothy Chapman, Mr. Jim Cootes, and Talaandig people of MKaRNP.

\section{References}

1. de Boer H, Newman M, Poulsen AD et al. (2018) Convergent morphology in Alpinieae (Zingiberaceae): Recircumscribing Amomum as a monophyletic genus. Taxon 67 (1): 6 - 36. doi: 10.12705/671.2.

2. Lamb A, Gobilik J, Ardiyani M, Poulsen AD (2013) A guide to gingers of Borneo. Kota Kinabalu: Natural History Publications (Borneo).

3. Kress WJ, Liu AZ, Newman M, Li QJ (2005) The molecular phylogeny of Alpinia (Zingiberaceae): A complex and polyphyletic genus of gingers. American Journal of Botany 92 (1): 167 - 178. doi: 10.3732/ajb.92.1.167.

4. Pelser PB, Barcelona JF, Nickrent DL (eds.) (2011 onwards) Co's digital flora of the Philippines. www.philippineplants.org. Accessed date: June, 2017.
5. Naive MAK (2017) Zingiberaceae of Kalatungan Mountain Range, Bukidnon, Philippines. Bioscience Discovery 8: 311319.

6. Elmer ADE (1915) Notes and description of Zingiberaceae. Leaflets of Philippine Botany 8 (116): 2885 - 2919.

7. Merrill E (1922) An enumeration of Philippine flowering plants. Vol. 1, Manila: Bureau of Printing.

8. Smith RM (1990) Alpinia (Zingiberaceae): a proposed infrageneric classification. Edinburgh Journal of Botany 47 (1): 1 - 75. doi: 10.1017/S0960428600003140

9. Beentje H (2016) The Kew Plant Glossary, an illustrated dictionary of plant terms. Second edition. Kew: Kew Publishing, Royal Botanic Gardens.

10. IUCN Standards and Petitions Subcommittee (2017) Guidelines for Using the IUCN Red List Categories and Criteria. Version 13. http://www.iucnredlist.org/documents/RedListGuidelines.pdf. Accessed date: September 1, 2017.

11. Ridley HN (1909) The Scitamineae of the Philippine Islands. Philippine Journal of Science 4: 155 - 199. 